\title{
CAD-CAM Implants in Esthetic and Reconstructive Craniofacial Surgery
}

\author{
Th. Hierl ${ }^{1}$, G. Wollny ${ }^{2}$, F.P. Schulze ${ }^{3}$, E. Scholz ${ }^{4}$, J.G. Schmidt ${ }^{5}$, G. Berti ${ }^{5}$, \\ J. Hendricks ${ }^{1}$ and A. Hemprich ${ }^{1}$ \\ ${ }^{1}$ Dept. of Oral and Maxillofacial Plastic Surgery; Leipzig University, Germany \\ ${ }^{2}$ Max-Planck-Institute of Evolutionary Anthropology; Leipzig, Germany \\ ${ }^{3}$ University of Applied Sciences, Fac. of Engineering; Leipzig, Germany \\ ${ }^{4}$ University of Applied Sciences, Fac. for CAD; Leipzig, Germany \\ ${ }^{5} \mathrm{C} \&$ C Research Labs. NEC Europe; St. Augustin, Germany
}

In the reconstruction of complex craniofacial malformations CAD-CAM procedures could help generating alloplastic implants to achieve almost optimal esthetic results. Complementary to the existing CAD-CAM techniques in the cranial vault region or modeling procedures in unilateral defects, these techniques are introduced to bilaterally affected skulls in esthetic reconstructive surgery. Surgery could thus become less invasive and results more predictable. A tool chain is shown to generate such implants on scientific basis. 3D cephalometric analysis is performed and the implants are designed according to the individual pathology. Besides the planning of implants on the basis of 3D-landmarks, future implant design is supposed to be performed with the help of a craniofacial library taken from CT-scans of unaffected skulls.

Keywords: CAD-CAM, implants, esthetic and reconstructive surgery

\section{Introduction}

During the last 10 years, techniques for manufacturing CAD-CAM implants have been developed to reconstruct skull defects in trauma or oncological cases (EUFINGER et al. 1998, SCHIPPER et al. 2004). In contrast to conventional surgical approaches using autogenous bone (e.g. split calvarial bone grafts (KIYOKAWA et al. 1998)), CAD-planned implants can cover large defects without the necessity of donor site morbidity and offer, at least in theory, optimal shape. Made out of titanium or ceramics (EUFINGER et al. 1998; HOFFMANN et al. 1998) in most cases, they offer superior stability and rigidity in contrast to prefabricated polyethylene, PTFE or PMMA implants. By now, CAD-CAM manufactured craniofacial implants have been mainly used for reconstructing the cranial vault due to the rather simple way of designing the "missing piece" (and due to the problems of harvesting large parts of autogenous bone) or by mirroring defective parts after trauma or ablative surgery (CIOCCA et SCOTTI 2004, EUFINGER et WEHMÖLLER 2002). In this paper, the use of CAD-CAM procedures will be discussed for esthetic and reconstructive surgery in the anatomically complex midfacial area and first results are presented.

\subsection{Requirements for CAD-CAM Procedures}

In a large number of craniofacial syndromes like Treacher Collins syndrome or Apert and Crouzon syndrome the midface is affected by a bilateral hypoplastic bony "infrastructure" and to a variable degree by deficiency of the surrounding soft tissues (Fig. 1).

In hemifacial microsomia the situation is different with more or less pronounced asymmetry whereas cleft lip and palate patients often present asymmetry or bilateral hypoplasia depending on the individual expression of the disease. In case of trauma or after ablative surgery, the resulting defects are often located in the midline making mirroring impossible.

By now, routine surgery would address these problems by transplanting autogenous cranial or iliac crest bone to correct the deficiency. The amount needed and the resulting shape will be 


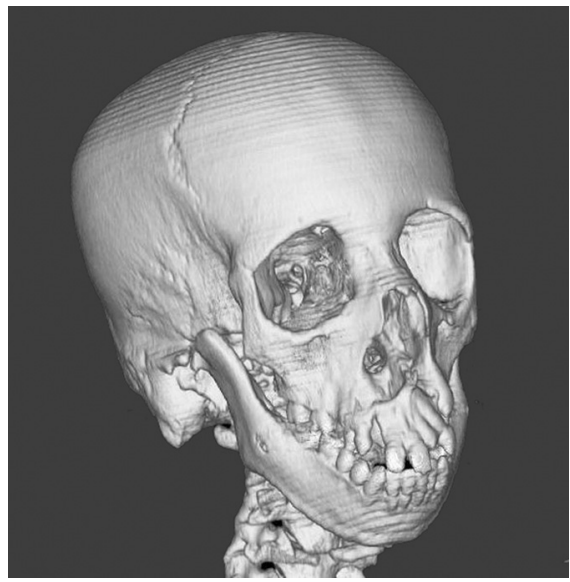

Fig. 1. CT reconstruction of a syndromic patient suffering from Roberts syndrome. Bilateral midfacial hypoplasia, orbital dystopia, bilateral cleft lip and palate, as well as mandibular hypoplasia, can be seen

(CT reconstruction via Vworks, Cybermed Inc.)

controlled by the surgeon depending on experience and skill. Having gained a deep insight into the intricacies of bony resorption and remodeling, an experienced surgeon may cope with these problems, too. Nevertheless, it would be difficult to state that these problems are easy to solve, even with the help of intraoperative navigation to control placement of the bone grafts. Here CAD-CAM procedures could offer a substantial improvement, as these implants can be precisely designed to any shape, can be inserted via less invasive approaches, should cut down operation time and will not show resorption or remodeling. To design these implants, however, special software is needed.

- First of all, a module is needed to analyze the existing situation. Besides simple measurement capabilities of an angulation or distance, a real thorough analysis like in orthodontic cephalometry would be needed.

- Secondly, the CT-data needs to be manipulated (cut, remove artifacts from dental fillings, and export into a CAD format).

- The next step is constructing the implant which should follow anthropometric guidelines then artistic inspiration.

- Ideally, there should be a software module to analyze the effects after implant insertion to quantify the results and check for mistakes.

By now, software solutions are only partially available. Therefore a tool chain is being developed at our study group which consists of commercially available products and self developed modules. The software should be easy to handle, run on normal hardware and be reasonably priced.
After planning the implant, the question is how this should be transferred into the desired material. Again, this should be as cheap as possible as there is always a lack of funds in any hospital environment and precision should be in the range of the preoperative data. For complex geometries the following established procedures seem to be reasonable:

- One option is to mill the implants (titanium or ceramics) which can be done precisely, but is expensive.

- The implants could be manufactured via rapid prototyping in plastic material, then invested and cast in titanium which is fast, precise and least expensive.

Modeling the implants directly on a rapid prototyping model in wax (GRONET et al. 2003) or in composite would be the fastest method, but it would not allow CAD-planning on a scientific basis.

\section{Methods for CAD-CAM}

The tool chain used for CAD consists of the following parts:

A tool for three-dimensional cephalometric analysis of the existing pathology. This tool will also serve for data acquisition in "normal" patient groups to gain data for comparative studies. CT data (in our study, protocol data aquisiton is done with $1 \mathrm{~mm}$ contiguous slices) is imported and visualized via the iso-values. Any anatomical or surgical landmarks may be defined on soft and hard tissue. The coordinates serve to define the 3D-analysis of angulations, distances or proportions. Also, symmetry analysis is facilitated that way (Fig. 2) (HIERL et al. 2005).

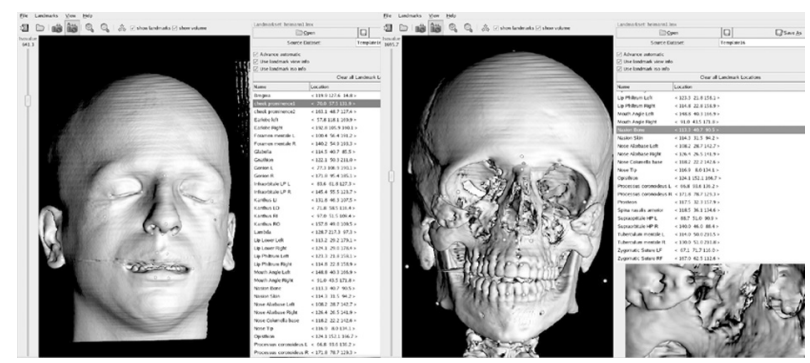

Fig. 2. Example of soft and hard tissue analysis. On the far left the iso-value slider is seen to display hard or soft tissue. The chosen landmarks are shown with the

coordinates. In the small window right below, a template is given to demonstrate the correct landmark position. 
To segment, cut CT data, remove artifacts and convert it into a proprietary CAD format, commercially available software is used. Here, Vworks (Cybermed Inc. Korea) was chosen as it allows easy segmentation, has excellent volume rendering capacities and runs fast on a standard PC.

For CAD construction Catia V5 (Dassault Systemes, France), a standard software for complex CAD construction was used. Construction was performed on the basis of 3D cephalometric measurements and was described in detail in ARNOLD 2005.

To compare the pre- and postoperative situation, a software for time series analysis was developed. Here, two scans can be compared and displacements of hard or soft tissue are calculated. Measurements are possible via colour code, metric data or the displacement vectors (Fig. 3) (WOLLNY et al. 2002).

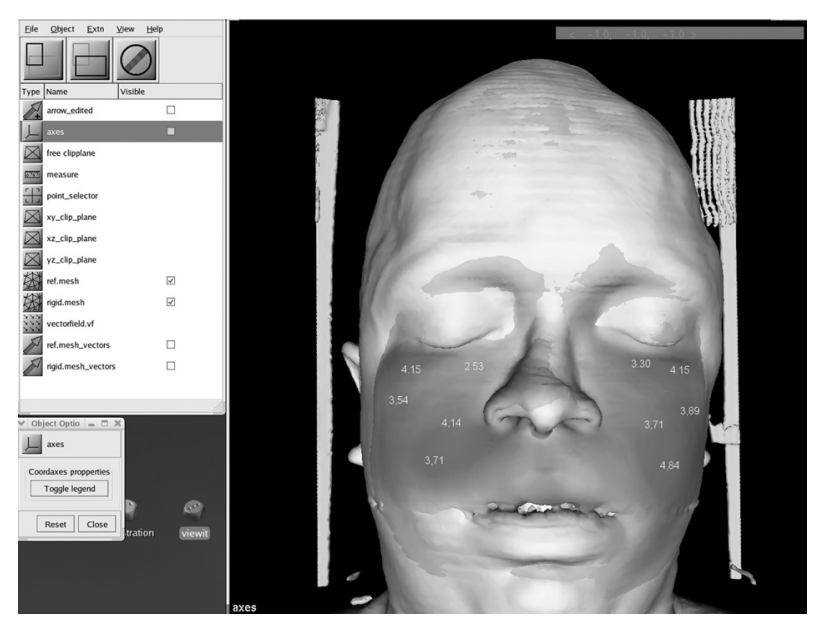

Fig. 3. Postoperative soft tissue changes visualized via colour coding (intensity reflects distance) and by showing the displacement distances.

To manufacture the implants, the least expensive way in our hands was to generate the implants in a rapid prototype machine via fused deposition modeling (FDM) (Titan Systems, Stratasys, Germany) in ABS (acrylnitrile-butadiene-styrene) (GRONET et al. 2003). ABS is robust, may be modified afterwards by milling, drilling or adding material and can be invested in a dental laboratory. It burns completely and the form created can be cast in titanium (Tritan, grade 1 titanium in implant quality, Dentaurum, Germany). In contrast to ceramics, titanium can be processed with thin sharp edges, almost without any gap to the underlying structures and it does not break when bent or when falling on the table surface.

\section{Evaluation of Soft- and Hardware Accuracy}

Before starting to produce implants, the accuracy of the software tool chain and of implant generation had to be evaluated. Therefore, titanium bone markers were inserted in five cadaver skull specimens and distances were measured directly by way of calibrated precision calipers and after CT scanning ( $1 \mathrm{~mm}$ contiguous slices, no overlapping) in our analysis software. Then the CT-data was segmented and exported into STL-format and rapid prototyping models were created on the FDM machine in ABS. Again, the distances between the bone markers on the FDM model were measured and compared to the real skull. At last, the skull specimens were "operated" by way of midfacial advancement and scanned again. Displacement data was measured in the time series module and directly on the skulls.

\subsection{Results}

Looking at the 3D cephalometric tool, analysis of 323 measurements showed an average deviation of $0.6 \mathrm{~mm}(0.5 \%)$ (maximum $1.8 \mathrm{~mm}$ ), which was below the expected accuracy of the $\mathrm{CT}$ scanning protocol. Comparing the FDM specimens with the real ones, average deviation lay at $0.25 \mathrm{~mm}(1.1 \%)(\max .0 .76 \mathrm{~mm})$, which was judged excellent. In the time series analysis, $80 \%$ of 545 measurements lay below $2 \mathrm{~mm}$, which was judged as the maximum inherent error due to the scanning at $1 \mathrm{~mm}$ at two times (average deviation $1.6 \mathrm{~mm}$ ). In $20 \%$ of cases displacement vectors were erroneous by not ending or starting on the surface which was, however, easily discernable (HENDRICKS 2005).

\section{Clinical Example}

The patient was a 29-ys.-old female suffering from Treacher Collins syndrome. 10 years ago, reconstruction of the hypoplastic midface was 


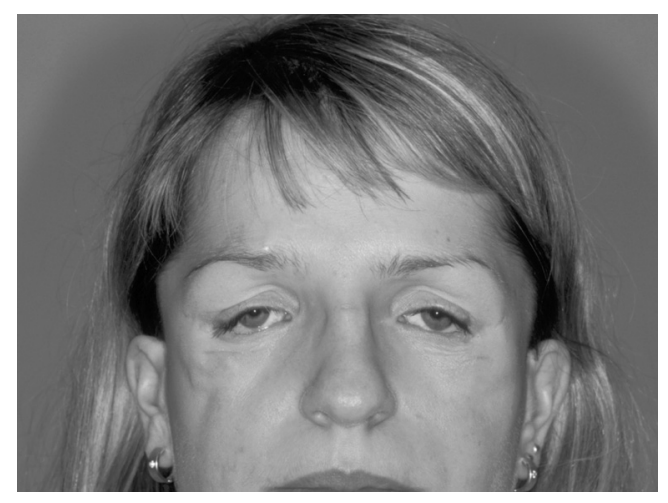

Fig. 4. Clinical appearance.

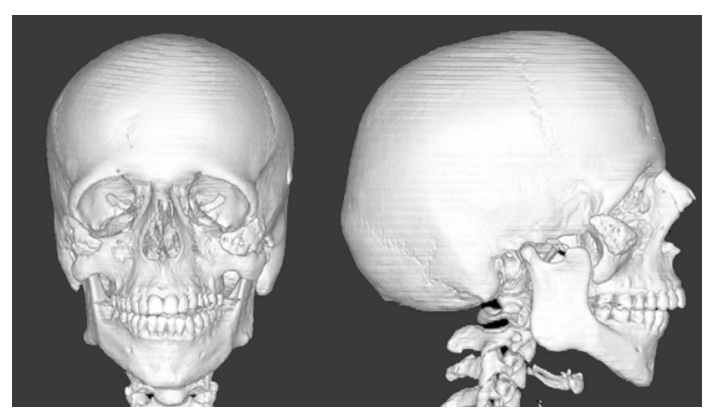

Fig. 5. CT scanning showing the absent zygomatic arch, deficient midface and onlay cartilage graft.

done by transplanting allogenic banked rib cartilage which led to a inacceptable esthetic situation (Figs. 2, 4 and 5).

According to the 3D-analysis, bilateral implants were created and cast in titanium (Figs. 6,7) and fixed with titanium micro screws.

Then the implants were inserted via small intraoral incisions and fixed with titanium miniscrews. Fig. 8 shows the postoperative situation.

\section{Future Perspectives}

At the beginning, we used 3D-cephalometric data to construct the implants. By now, $100 \mathrm{CT}$ scans have been evaluted to gain normative 3D data for the midfacial region. To construct large, geometrically complex parts, different ways of constructing rather than using anatomical landmarks as key points may be reasonable. Therefore a library of facial regions is created from routine $\mathrm{CT}$ scans (e.g. zygoma, forehead, chin, mandibular angle).

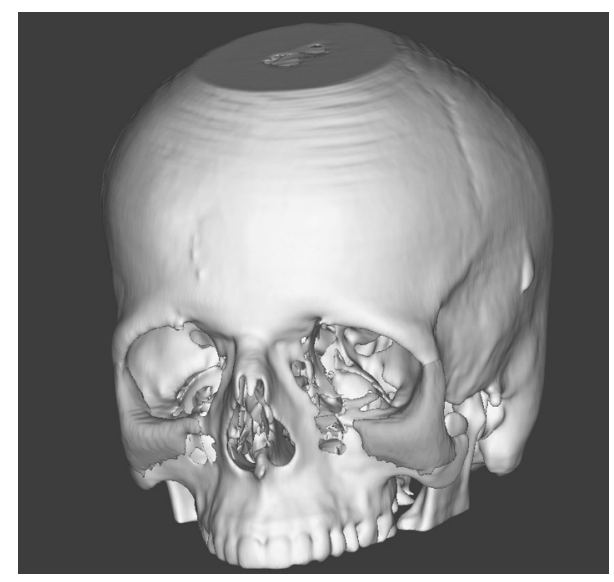

Fig. 6. Skull with the modeled zygoma implants after subtracting the cartilage grafts.

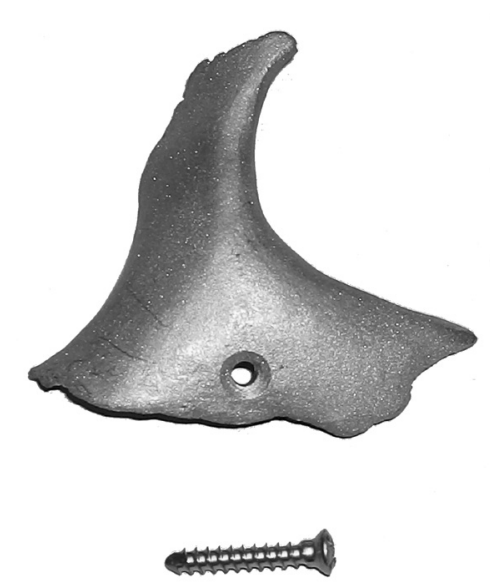

Fig. 7. Titanium implant after finishing. The miniscrew for fixation is shown below.

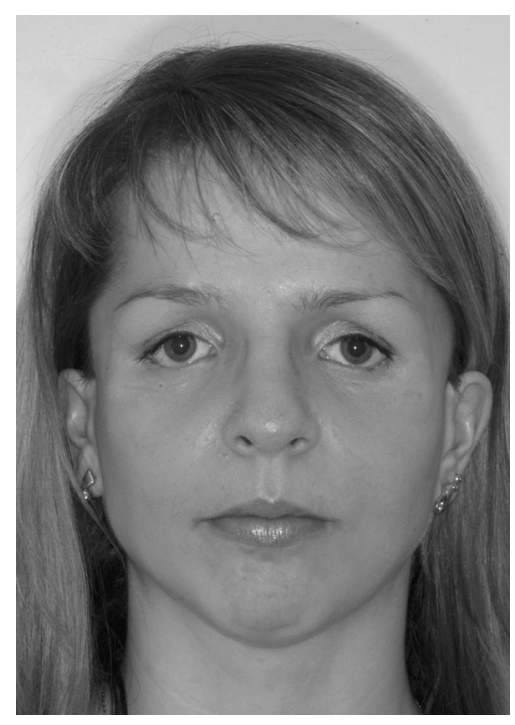

Fig. 8. Postoperative situation, improved esthetic appearance. 


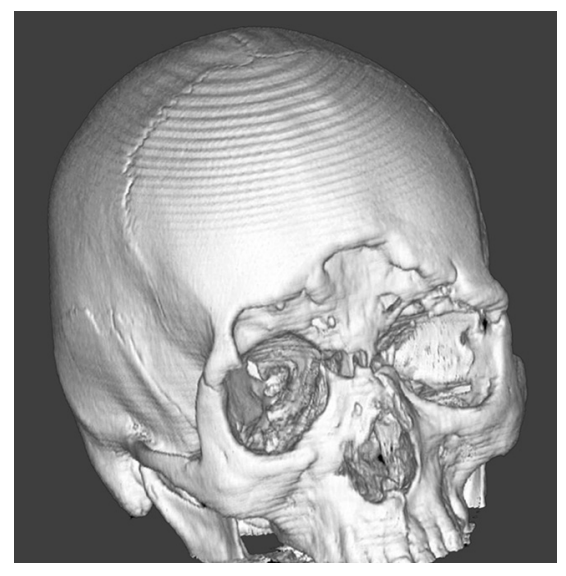

Fig. 9. Defect of the supraorbital rim, nasal base and frontal bone after trauma.

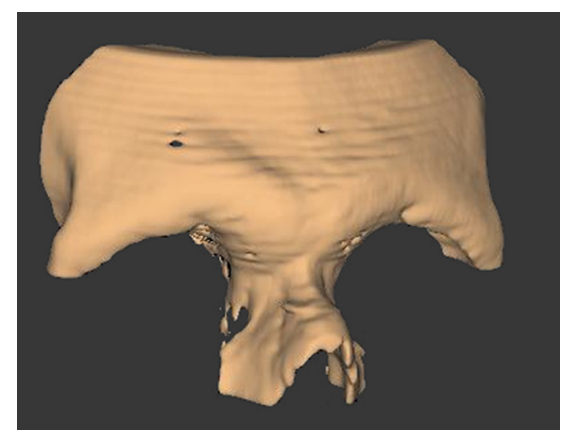

Fig. 10. Module taken from the library.

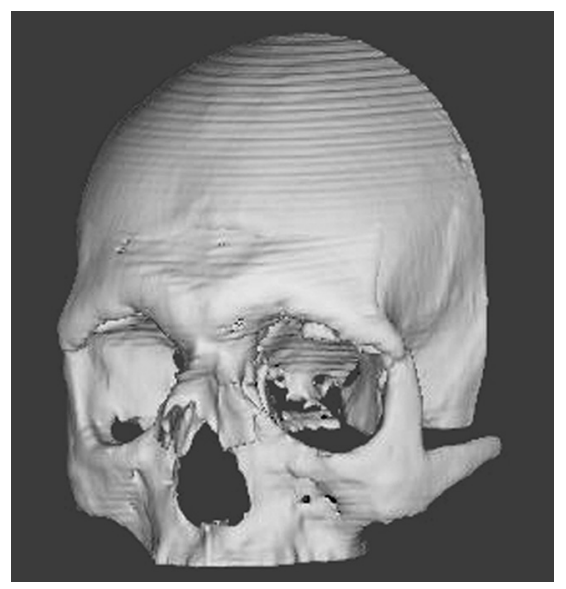

Fig. 11. Overlay of defective skull and module.

Parts are cut and proceeded with our above described tool chain. These specimens can be combined with pathological patient data enabling fast construction. Fig. 9 shows a severe midline defect of the nose, supraorbital rim and forehead. Simple mirroring or following the existing curvatures would not lead to an anatomical correct implant design. Therefore a nasoethmoidal module was taken from the li- brary and combined with the patient skull. Only minor adaptation of the edges is necessary.

As all skulls serving as our modules are threedimensionally analyzed, comparison of patient data of the whole skull to the library data should lead to the best suited module and is planned for the future.

A question not yet addressed by any investigation is the behaviour of the soft tissues after implant insertion. In theory, different ways are possible. Soft tissue could flow symmetrically around the implant, its thinning being dependant on the amount of stretching and on material properties. On the other hand, displacement into "favourite" regions could occur. As the behaviour is not known yet, evaluation of soft tissue reaction will be a major task in the future. This should improve implant design as the major task in esthetic surgery is to restore facial contour and not the underlying bone. Simulation software has been developed and it will be evaluated in the near future (BERTI et al. 2004). For follow-up studies pre- and postoperative surface scanning is the method of choice to learn more and it is performed at our study group.

\section{Conclusion}

CAD-CAM-manufactured individual implants can serve as an almost perfect means to reconstruct facial deficiencies in complex situations. At our department 11 implants have been made during the last year $(2 \times$ forehead, $6 \times$ zygoma, $1 \times$ chin, $2 \times$ mandibular angle). Compared to preformed implants, these offer perfect design and fit. In no case infection or other postoperative problems have been encountered. Being tightly secured by titanium miniscrews, implant dislocation is highly improbable. With the help of a suitable software and a sufficient data library, CAD-CAM implants could be a major improvement in planning esthetic facial plastic and reconstructive surgery. Regarding the costs, CAD-CAM implants still rank at the top end. It remains to be seen, whether appropriate software and production costs will enable the use of CAD-CAM procedures in a wide range of patients. 


\section{Acknowledgement}

We would like to thank the Dept. of Radiology and the Dept. of Anatomy for their kind cooperation.

\section{References}

[1] S. ARNOLD, Konstruktion individueller Implantate in der Craniomaxillofazialen Chirurgie mit CATIA V5 (Construction of individual implants in craniomaxillofacial surgery with CATIA V5). Diploma Thesis, University of Applied Sciences Leipzig (2005).

[2] G. Berti, J. FingBerg, T. HiERL, J.-G. SCHMidT, An interactive planning and simulation tool for maxillo-facial surgery. In: Perspectives in imageguided surgery ( TH. M. Buzug, T. C. Lueth, Ed.) (2004) pp. 872-879. World Scientific Publishing.

[3] L. CiocCA, R. ScotTI, CAD-CAM-generated ear cast by means of a laser scanner and rapid prototyping machine. J Prosthet Dent 92 (2004), pp. 591-595.

[4] H. Eufinger, M. WeHMÖLLER, Microsurgical tissue transfer and individual computer-aided designed and manufactured prefabricated titanium implants for complex craniofacial reconstruction. Scand $J$ Reconstr Surg Hand Surg, 36 (2002), pp. 326-331.

[5] H. EufingeR, A.R.M. WitTKAMPF, M. WeHMÖLLER, F.W. ZONNEVELD, Single-step frontoorbital resection and reconstruction with individual resection template and corresponding titanium implant: a new method of computer-aided surgery. $J$ Craniomaxillofac Surg 26 (1998), pp. 373-378.

[6] P.M. GRONET, G.A. WASKEWICZ, C. RichaRdSON, Preformed acrylic cranial implants using fused deposition modeling: a clinical report. J Prosthet Dent 90 (2003), pp. 429-433.

[7] J. HENDRICKS, Analyse der Mittelgesichtsdistraktion anhand neuer dreidimensionaler CTUntersuchungsmethoden (Analysis of midfacial distraction osteogenesis with new three-dimensional CT methods) Med. Dissertation Leipzig University (2005).

[8] Th. Hierl, G. Wollny, J. Hendricks, G. Berti, J.G. SCHMIDT, J. FingBERG, A. HEMPRICH, 3DAnalysis of soft tissue changes following maxillary distraction osteogenesis. In: Reconstruction of Soft Facial Parts BKA Series 31-2: Police and Research. (T.M. Buzug, K. Prüfer, K. Sigl, J. Bongartz, P. Hering, G. Willems Ed.), (2005) Luchterhand Publishers, in press.

[9] J. Hoffmann, C.P. Cornelius, M. Groten, L. PRÖBSTER, C. PFANNENBERG, N. SCHWENZER, Orbital reconstruction with individually copy-milled ceramic implants. Plast Reconstr Surg 101 (1998), pp. 604-612.
[10] K. KiYOKAWA, K. HAYAKAWA, H.Y. TANABE, Y. INOUE, Y. TAI, M. SHIGEMORI, T. TOKUTOMI, Cranioplasty with split lateral skull plate segments for reconstruction of skull defects. J Craniomaxillofac Surg 26 (1998), pp. 379-385.

[11] J. SCHIPPER, G.J. RidDER, U. SPETZGER, C.B. TESZLER, M. FRADIS, W. MALER, Individual prefabricated titanium implants and titanium mesh in skull base reconstructive surgery. A report of cases. Eur Arch Otorhinolaryngol 261 (2004), pp. 282-290.

[12] G. Wollny, TH. HieRL, F. KRUGGEL, R. KLÖPPEL, Die Analyse von Zeitreihenaufnahmen am Beispiel einer suturalen Mittelgesichtsdistraktion. In: Bildverarbeitung für die Medizin 2002 (M. Meiler, D. Saupe, F. Kruggel, H. Handels, T. Lehmann Ed.) (2002) pp. 63-66. Springer-Verlag Berlin, Heidelberg.

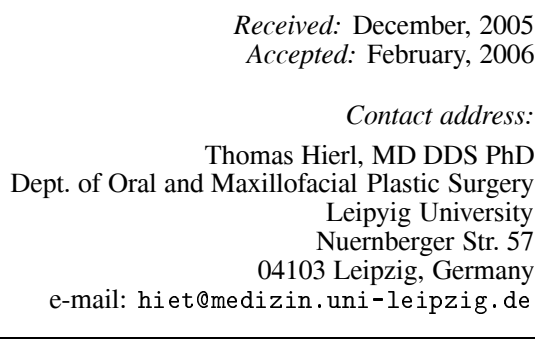

THOMAS HIERL is consultant at the Dept. of Oral and Maxillofacial Plastic Surgery at Leipzig University and works in the field of reconstructive plastic facial surgery. His fields of interest are surgery simulation in facial plastic and orthognathic surgery, CAD-CAM procedures, and craniofacial anomalies.

GERD WOLLNY has graduated from mathematics at Leipzig University and made his PhD at Max-Planck-Institute of Cognitive Neurosciences Leipzig on time series analysis of CT and MRI images. He is currently affiliated with the Max-Planck-Institute of Evolutionary Anthropology, Leipzig. His major field of work is visualization, registration, and segmentation of 3D images.

FRITZ PETER SCHULZE holds the position of a professor at the University of Applied Sciences, Leipzig, Department of Mechanical and Energy Engineering. His specialities are manufacturing engineering and machine tools, especially rapid prototyping techniques.

ECKHARD SCHOLZ also holds the position of a professor at the University of Applied Sciences, Leipzig, Department of Mechanical and Energy Engineering. His specialities are CAD and software techniques.

JENS GEORG SCHMIDT has received his diploma and $\mathrm{PhD}$ in mathematics. He is currently affiliated with the NEC C \& C Research Laboratories in St. Augustin, Germany. His main scientific interest lies in research on parallel computing in finite element analysis for solving biomechanical problems.

GUNTRAM BERTI has received his diploma and PhD in mathematics. He is currently affiliated with the NEC C \& C Research Laboratories in St. Augustin, Germany. His scientific interest lies in generic software components for scientific computing.

JOERG HENDRICKS has a degree in medicine and is affiliated with the Dept. of Oral and Maxillofacial Plastic Surgery at Leipzig University. His fields of interest lie in 3D analysis of the facial skeleton and visualization techniques.

ALEXANDER HEMPRICH is the head of the Dept. of Oral and Maxillofacial Plastic Surgery at Leipzig University. His major fields of interest lie in diagnostics and treatment of craniofacial anomalies. 